\title{
Adenosina deaminasa en fiebre tifoidea y otras enfermedades febriles
}

\author{
Víctor Casanueva E. ${ }^{1}$; Ximena Cid $\mathbf{C}^{2}$; Gilda Cavicchioli B. ${ }^{2}$; \\ Margarette Oelker B. ${ }^{1}$; Julián Cofré C. $^{3}$

\begin{abstract}
Adenosine deaminase: activity in typhoid fever and other febrile conditions
\end{abstract}

\begin{abstract}
The contribution of serum adenosine feaminase (ADA) activity to the diagnosis of typhoid fever was assessed in 246 children and in 46 adults, by Giusti's original technique ${ }^{5}$. Children included otherwise healthy patients admited for elective surgical conditions or under follow up for epilepsy whlch were considered to be a control group (n: 81), presumptive viral diseases (n: 31 ), miscellaneous febrile diseases except for typhoid fever (n: 411 . different kinds of bacteremia ( $n$ : 6), diarrhea due to Sslmonella typhimurium $(n: 14)$, viral hepatitis ( $n$ : 24 ), and culture proven typhoid fever in: 491 . Adult's group included 39 healthy controls and 7 patients with culture proven typhoid fever. Among children mean ADA activity was as follows: control group $28 \pm 7.8$. viral desease $35.3 \pm$ 13.1, miscellaneous febrile disease $36.1 \pm 15.6$, bacteremia group: $30.3 \pm 10.3$. salmonelossis group $51.6 \pm 9$, hepatitis group $68.3 \pm 34.5$, typhoid fever group $124.4 \pm 40.8 \mathrm{U} / \mathrm{k} 37^{\circ} \mathrm{C}$. Arrong adults, values were $18.4 \pm 7.5$ for controls and $112.8 \pm 19.2 \mathrm{U} / 137^{\circ} \mathrm{C}$ in typhoid fever patients. In both adults and children ADA activity was signi. ficantly higher in the typhoid fever group [ $p<0.0001$ ). Untreated typhoid fever patients had their higher ADA activity between 10 th and 15 th day of iltness. When ADA cut point was set at $80 \cup /$, sensitivity of the test was $91.8 \%$ and specificity was $91.4 \%$ as a preliminary clue to the recognition of typhoid fever
\end{abstract}

(Key words: Adenosine deaminase, serum, typhoid fever.)

La enzima adenosina deaminasa (ADA) actúa en el catabolismo de las purinas, catalizando la transformación de adenosina en inosina y de 2-desoxiadenosina en 2-desoxinosina respectiva. mente ${ }^{1}$. En el suero existen dos isoenzimas, ADA 1 y ADA $2^{2}$. Su mayor actividad se encuentra en el tejido linfoide, especialmente en los linfocitos $T$, variando según la diferenciación de ellos, por lo que sirve como marcador de actividad de la inmunidad celular ${ }^{3}$. En todas las enfermedades que presentan ese tipo de respuesta inmunitaria la ADA sérica está aumentada: fiebre tifoidea ${ }^{4}$, mononucleosis infecciosa, hepatitis vírica, brucellosis ${ }^{5}$ y derrame pleural tuberculoso. el cual ha sido ampliamente estudiado en nuestro pais ${ }^{6,7}$.

Muchas veces se encuentran pacientes con fie-

1. Departamento de Pediatría. Facultad de Medicina. Universidad de Concepción.

2. Laboratorio Central, Hospital Gullermo Grant Benavente. Concepción.

3. Servicio de Pedintría. Hospita] Guillermo Grant Benavente. bre de curso prolongado, cuya etiologia no es posible determinar por la anamnesis y el examen físico. Por su prevalencia y las condiciones de muestro pais, una primera hipótesis es la fiebre tifoidea; sin embargo, su confirmación precoz no es fácil ya que los métodos clásicos presentan ciertas desventajas, como demora de los resultados, rendimiento variable de los cultivos ${ }^{8-11}$ : poca especificidad de las reacciones de aglutinación $^{12}$, y por último, en pacientes tratados con antibióticos, disminución de aislamientos positivos en los cultivos ${ }^{13}$. Es necesario investigar un método rápido, de bajo costo, que no sea afectado por los antibióticos, que tenga buen rendi. miento y permita orientar el diagnóstico en los pacientes con fiebre. En un informe preliminar nos hemos referido a la utilidad de la ADA en fiebre tifoidea $y$ a sus valores de referencia en niños $y$ adultos ${ }^{14}$. El objetivo de este trabajo es describir su actividad sérica en diversas enfermedades febriles, determinar su sensibilidad, especificidad y valor predictivo en el diagnóstico de fiebre tifojdea y mostrar su evolución en pacientes que han recibido tratamiento específico. 


\section{Material y Método}

Se determinó la actíidad de la enzima adenosina deaminasa en un estudio prospectivo de caso y control en el suero de 292 pacientes, 246 niños y 46 adultos, de edades entre 1 a 14 y 19 a 45 años, respectivamente, ingresados al Hospital Guillermo Grant Benavente de Concepción, entre los meses de marzo de 1988 y junio de 1990. Las muestras fueron enviadas al laboratorio sin expresión đel diagnóstico.

Los niños se dividieron en 7 grupos: un grupo control formado por $\mathbf{8 1}$ pacientes que ingregron para ser operados en otorinolaringología y cirugía infantil o epilépticos en tratamiento. El segundo grupo comprendía 31 nifros, cuyo diagnóstico de egreso fue infección presuntamente viral, por descarte de otras afecciones $y$ en tase a hechos clínicos y evidencia de laboratorio. En el tercero se incluyeron 41 niños con síndrome febril, en los cuales se descartaron infeccio. nes por Salmonella typhi mediante cultivo y estaba constituido pot infecciones utinarias (n: 10), shigello. sis ( $n ; 2)$, gastroenteritis (n: 3 ), diarcea aguda (n: 1), bronconeumonías ( $n: 10$ ), artuitis (n: 3 ), sarampión (n: 1$)$, meningoencefalitis ( $n: 2$ ), varicela (n: 1), quiste hidatídico (n: 1), apendicitis (n: 5), tuberculosis (n: 2 ). E1 cuarto correspond ia a 6 niños que presentaban septicemia por germen gram positivo (n: 3) y gram negativo (n: 3). El quinto grupo estaba formado por 14 niños afectado por un brote hospitakrio de diartea debida a Salmonella typhimurium, comprobada con hemocultivos, mielocultivos o coprecultivos. En el grupo seis se incluyeron 24 nifios cuyo diagnóstico clínico $y$ de laboratorio era hepatitis viral. El séptimo grupo comprendía 49 niơos con tiagnóstico de fiebre tifoidea, comprobado con sus respectivos cultivos en todos los casos.

Los adultos se dividieron en 2 grupos: $\infty$ ntrol, compuesto por 39 donantes del banoo de sangre del mismo hospital, $y$ otro de 7 pacientes hospitalizados con fiebre tifoidea confirmada mediante hemocultivos.

Ia actividad de la adenosina deaminas sérica se determinó mediante la técnica or iginal de Giusti ${ }^{5}$, modificando la longitud de onda de medición de 630 a $578 \mathrm{~mm}$. Este es un método colorimétrico en el que la adenosina es transformada en inosina por la acción de ADA, produciéndose $\mathrm{NH}_{3}$ que reacciona con hipoclorito de sodio $y$ fenol (empleando nitroprusiato de sodio en medio alcalino como catalizador) para formar indofenol. Las lecturas se realizaron en un fotómetro Clinicon 4.010 frente a un blanco de reactivo y la actividad de la ADA sérica se expresó en $\mathrm{U} / \mathrm{t}$ a $37^{\circ} \mathrm{C}$. En el análisis de la significación estadística de las diferencias observadas se utilizó la prueba de Students.

\section{Resultados}

En la figura 1 se muestra la distribución y al pie de ella se expresan los valores promedio de actividad de $A D A$ en los grupos estudiados. En los nir̂̃os controles la concentración de ADA en el suero fue $28,0 \pm 7,8 \mathrm{U} / 1$ y en controles adultos
$18,4 \pm 7,5 \mathrm{U} / \mathbf{1}$, diferencia que resultó estadísticamente significativa $(\mathrm{p}<0,001)$. Los promedios de actividad sérica de ADA fueron significativa. mente mayores en los pacientes con fiebre tifoidea $(124,4 \pm 40,8$ en niños y $112,8 \pm 19,2$ U/I en adultos) que en pacientes con las demás enfermedades ( $p<0,0001$ ). Considerando 80 U/1 como límite de actividad para diferenciar fiebre tifoidea de otras afecciones, 4 pacientes ( $8,1 \%$ de la muestra) que en momento de la deteminación llevaban 25 dís de evolución presentaron valores inferiores a esta cifra, $9(18,4 \%)$ tenian concentraciones séricas entre 80 y 100 U/1 y $36(73,5 \%)$ sobre $100 \mathrm{U} / 1$. En hepatitis se dieron algunos casos con actividad sérica de ADA sobre el límite de 80 , pero la enfermedad es fácil de descartar con las transaminasas y el estudio de función hepática.

En la tabla 2 se muestra un intento para reconstruir la evolución de la actividad de ADA en el tiempo transcurrido desde el comienzo de los sintomas clinicos de la fiebre tifoidea. En las mediciones realizadas en la primera semana su concentración ya estaba aumentada y el máximo de actividad de la enzima se produjo aproximadamente a $\operatorname{los} 15$ días de evolución, comenzando su descenso gradual alrededor de los 25 días en pacientes sin tratamiento. En la figura 2 se muestra la actividad de la enzima en 7 pacientes en tratamiento por fiebre tifoidea, observándose que en pocos días estaba bajo $80 \mathrm{U}$ en la mayoría de ellos.

La sensibilidad y especificidad de la respuesta enzimática de ADA para la identificación de fiebre tifoidea entre las causas estudiadas en esta serie fueron $91,8 \%$ y $91,4 \%$, respectivamente, al considerar como valor límite $80 \mathrm{U} / 1$ a $37^{\circ} \mathrm{C}$. El valor predictivo de la prueba positiva fue de $81 \%$ y el de la prueba negativa $96 \%$.

\section{Discusión}

La diferencia de la actividad sérica de ADA entre niños y adultos sanos podría deberse a la mayor actividad del timo en el niño. Los valores de ADA en fiebre tifoidea parecen ser una buena ayuda en el diagnóstico de esta enfermedad, por su diferencia altamente significativa con los valores de referencia y los obtenidos en enfermedades presuntamente virales, afecciones febriles de diversas causas, otras salmonelosis y hepatitis. Estas dos últimas mostraron, en algunas ocasio- 


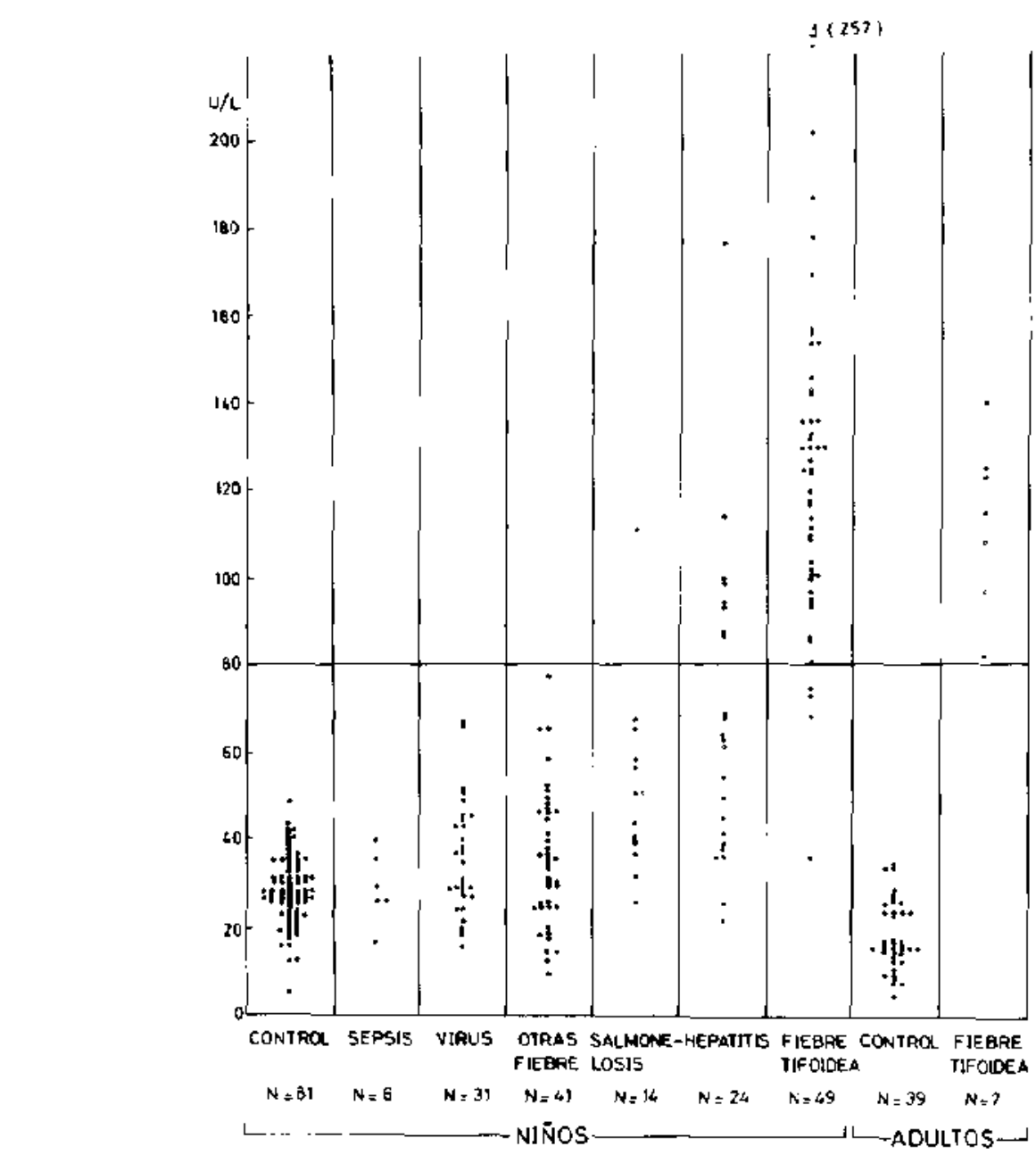

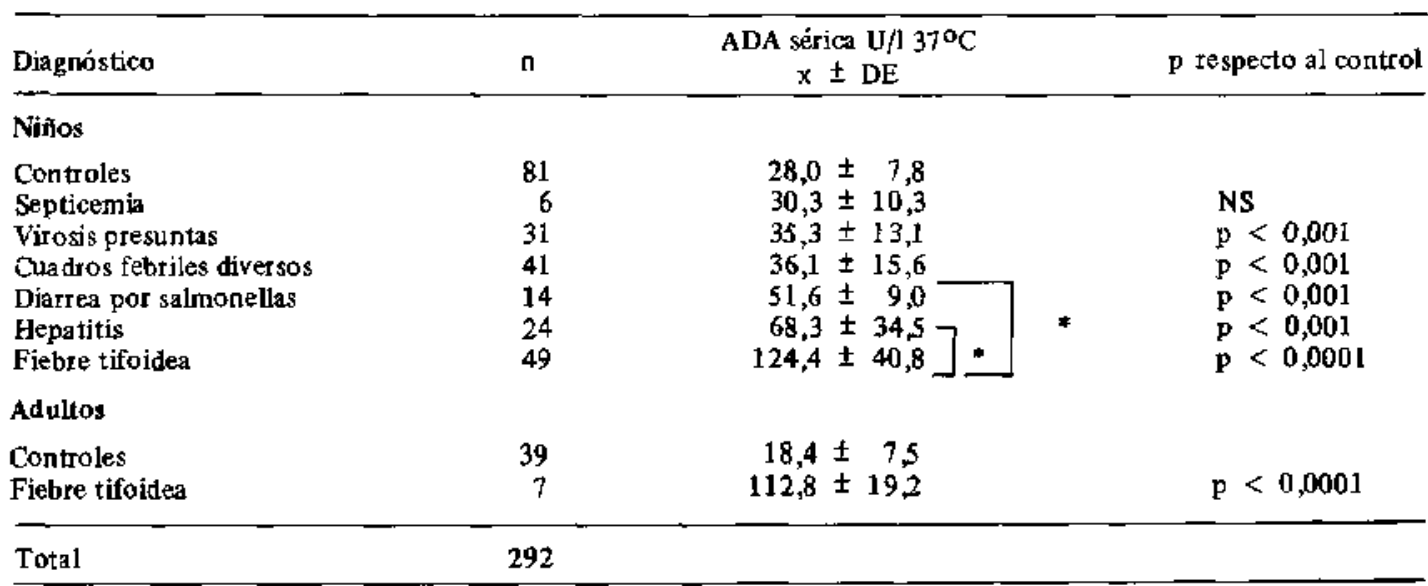

- $\mathrm{p}<0,0001$ fiebre tifoidea respecto a salmonelosis y hepatitis.

Figura 1: Actividad sérica de la adenosina deaminasa (ADA) en nifios y aduitos sanos y con flebre tifoidea y en rifios con otras enfermedades febriles. 
Tabla 1

ADA sérica en pacientes con fiebre tifoidea sin tratamiento

\begin{tabular}{|c|c|c|c|}
\hline $\begin{array}{c}n \text { días desde comienzo de } \\
\text { enfermedad }\end{array}$ & $n$ pacientes & \multicolumn{2}{|c|}{$\begin{array}{c}\text { Actividad ADA U } / 137^{\circ} \mathrm{C} \\
x \pm D E\end{array}$} \\
\hline $\begin{array}{r}4-9 \\
10-15 \\
16-21 \\
22-+\end{array}$ & $\begin{array}{r}23 \\
8 \\
4 \\
5\end{array}$ & $\begin{array}{r}127,2 \\
143,8 \\
116,8 \\
79,8\end{array}$ & $\begin{array}{l}38,9 \\
49,4 \\
32,7 \\
30,1\end{array}$ \\
\hline Total & 40 & & \\
\hline
\end{tabular}

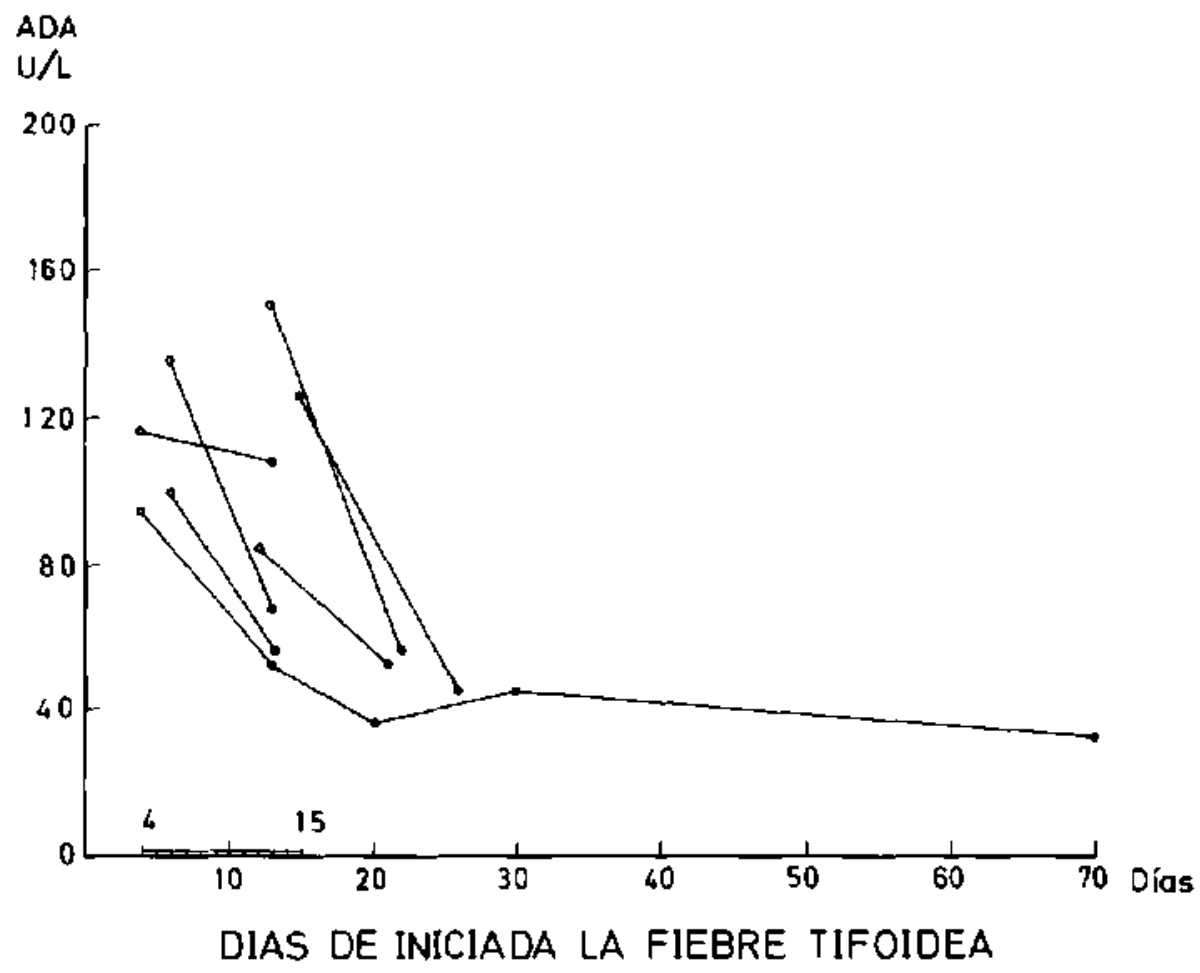

Figura 2: Seguimiento de ADA sérica de siete pacientes con tratamiento para fiebre tifoidea. $0=$ comienzo del tratamiento.

nes, actividades séricas de ADA similares a las de la fiebre tifoidea, pero son fácilmente identificables, la primera por sus manifestaciones clínicas de diarrea, que obedecía, además, en todos los casos de esta serie, a infecciones intrahospitala. rias y la segunda por sus signos, síntomas y las concentraciones séricas de transaminasas y bilirrubina.

La confirmación del diagnóstico de fiebre tifoidea por hemocultivos y mielocultivos adolece de ciertas dificultades, entre ellas la tardanza en el informe de los resultados con las consi. guientes demoras del tratamiento y prolongación de las molestias de los pacientes, la variabilidad de su rendimiento en diferentes circunstancias y los riesgos de complicaciones inherentes a la toma de muestras para mielocultivos $^{15-20}$. Las reacciones de aglutinación basadas en la aparición de aglutininas contra antígenos $\mathrm{O}$ y $\mathbf{H}$ de Salmonella typhi son poco confiables ya que, entre otras cosas, han sido descritas hasta en más de $40 \%$ de niños aparentemente sanos. Otros 
métodos inmunologicos más recientes y de mejor rendimiento como la búsqueda de anticuerpos IgM e IgG contra las porinas (proteínas antígenas de la membrana celular de la $S$. typhi) ${ }^{16}$, el empleo de sondas DNA específicas y los inmunoensayos enzimáticos con aniicuerpos monoclonales para los antígenos $\mathrm{O}, \mathrm{H}$ y $\mathrm{Vi}^{17}$ y ELISA $^{19}$, estân aún en fases experimentales o carecen de la sen sibilidad necesaria 0 , simplemente, están fuera de nuestro alcance.

En estas circunstancias, la medición de la actividad sérica podría ser de utilidad para orientar más precozmente hacia el diagnóstico de fiebre tifoidea, que en todo caso requiere, por el momento, de confirmación por cultivos.

La respuesta inmune del huésped a la Salmonella typhi es mediada por células, ya que es posible transmitir la protección mediante linfocitos, pero no mediante suero ${ }^{20}$, y se ha propuesto el empleo de la actividad de ADA como marca. dor de la actividad inmune mediada por células ${ }^{2 !}$.

Las salmonellas, en general, penetran hasta la lámina propia de la mucosa intestinal, desencadenando una respuesta celular a base de polimorfonucleares. La infección no se disemina más $y$, si ocurre, la bacteremia es transitoria y sin fo-

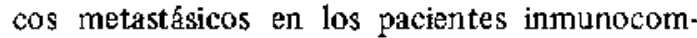
petentes. En cambio, la Salmonella typhi pasa rápidamente a la circulación genera], probable. mente a través de los linfáticos, para localizarse en las células del sistema reticuloendotelial, donde se multiplica, para volver desde ahí a la circulación. En la lámina propia la $S$. typhi origina una reacción celular a base de mononuclea. res, al parecer por inhibición de los mecanismos oxidativos de la fagocitosis en los polimorfonycleares, lo que le permite resistir la destrucción en el interior de estos leucocitos. Los monocitos, entonces, transportan los bacilos a los ganglios mesentéricos y al sistema reticuloendotelial $^{30}$ donde se multiplican, produciéndose hepatomegalia, esplenomegalia e hiperplasia de las placas de Peyer. E1 contacto intracelular sostenido explicarfa el aumento de la actividad de la ADA en la fiebre tifoidea.

Existe una correlación positiva entre la actividad de la ADA y la población de linfocitos $T_{4}$, llamados también $C_{4}$ o auxiliares. $E n$ un estudio de pacientes con tuberculosis pleural, utilizando anticuerpos monoclonales, la actividad de ADA aumentó en forma paralela a la estimulación antigénica de los linfocitos T. Al disminuir los antígenos, los linfocitos quedan en reposo, como sería el caso en el transcurso de la fiebre tifoide ${ }^{22}$.

En resumen, la determinación de la actividad de adenosina deaminasa puede ser de ayuda en el diagnóstico de la fiebre tifoidea. Se trata de un examen de fácil ejecución, al alcance de cualqujer laboratorio de mediana complejidad y de bajo costo; no obstante estas ventajas, no reemplaza a los métodos clásicos, sino que los refuerza, residiendo su mayor utilidad en la orientación precoz del diagnóstico y en el caso de pacientes con manifestaciones clínicas sugerentes de fiebre tifoidea y cultivos negativos.

\section{Resumen}

Con el propósito de evaluar su contribución en el diagnóstico diferencial precoz de la fiebre tifoidea se midió la actividad de adenosina deaminasa, mediante la técnica de Giusti, en el suero de 292 pacientes: 246 niños y 46 adultos. Entre los niños se incluyeron 81 pacientes sanos como control, 31 cuyo diagnóstico de egreso fue presunta infección a virus, 41 sujetos con síndrome febril de diversas etiologías, 6 niños con septicemias bacterianas, 14 con diarrea intrahospitalaria causada por Salmonella thiphimurium, 24 niffos con hepatitis y 49 pacientes con fiebre tifoidea. La muestra de adultos estaba formada por 39 controles sanos y 7 pacientes con fiebre tifoidea. Los resultados de la actividad de ADA ( \pm y DE, en $U / 1$ a $37^{\circ} \mathrm{C}$ ) en los niños fueron $10 \mathrm{~s}$ siguientes: controles $28,0 \pm 7,8$; presuntas virosis $35,3 \pm 13,1$, síndrome febril $36,1 \pm 15,6$, sepsis $30,3 \pm 10,3$, salmonelosis $51,6 \pm 9$, hepatitis $68,3 \pm 34,5$, fiebre tifoidea $124,4 \pm 40,8$. En los adultos: controles $18,4 \pm 7,5$ y fiebre tifoidea $112 \pm 19,2$. Se encontraron diferencias estadísticamente significativas entre controles niños y adultos y entre los pacientes con fiebre tifoidea y todos los demás grupos estudiados, incluyendo controles y pacientes con diarrea pot Salmonella typhimurium en la actividad sérica de adenosina deaminasa ( $\mathrm{p}<0,0001$ ). En pacientes con fiebre tifoidea no tratada la actividad máxima de la enzima se registró entre los días 10 y 15 de evolución de la enfermedad. La sensibilidad de la determinación de la enzima para orientar el diagnóstico hacia fiebre tifoidea fue de $91,8 \%$ y su especificidad $91,4 \%$ si se consideran sólo los pacientes con actividad de adenosina deaminasa de 80 o más U/1. Si bien este método no reem. plaza a los cultivos bacterianos, es de utilidad 
para orientar precozmente la identificación de pacientes con fiebre tifoidea.

(Palabris claves: fiebre tifoider, diagnóstico, adenosina deaminasa sérica.)

\section{Referencias}

1. Hoffmon, E.; Kopp, W.; Moar, A.: Enhanced antibody response in the presence of partial adenosine deaminase inhibition. Proc Soc Biol Med $1990 ; 194: 36-42$.

2. Muraoka, T.; Kotsumari, T.; Shiraishi, H.; Yokoyama, $M$. Automated enzymatje measurement of adenosine deaminase iso enzyme activities in serum. Anal Biochem 1990; $187: 268.272$.

3. Ribera, G.; Marrinez, J.; Ocafa, I.; Segura, R; Pacual, $C$.: Activity of ADA in CSF for diagnosis and follow up of tuberculous meningitis in adults. J Inf Dis 1987 ; 155: 603-607.

4. Galant, B.; Nardiello, S.; Russo, M.; Fiorentino, F. Increased Lymphocyte Adenosine deaminase in Typhoid Fever. Scand I Inf Dis 1981; 13: 47-50.

5. Giusti, $G$ : : Adenosine deaminase. In Bergmeyer, H.U. Edit. Methods of enzymatic analysis. New York AGdemic Press Inc. 1974; 1092-1099.

6. Mendozo, J.: May, J.; Gutiérrez, M.; Faccin, A.: Determinación de adenosina deaminasa (ADA) en líquido pleural. Utilidad en el diagnóstico de tuberculosis pleural. Boletín del Hospital San Juan de Dios (Santiago) $1989 ; 36: 12-15$.

7. Rodriguez, E.; Soto, F.; Velísquez, C.: Adenosina deaminasa como test diagnóstico de tuberculosis pleural. Enferm Respir Gír Torác 1987; 3: 182. 186.

8. Drobnic, L,; Tomé, J.: Salmonellosis tifoparatiffcas. Enfermedades infecciosas y Microbiología Cinica. 1986; 4: 3117-3128.

9. Salcedo, M.; Jiménez, L.: Conductas Clínico-Terapéuticas en la Fiebre Tifoidea y Paratifus 1 era. parte. Revista Chilena de Infectolog ía 1984; 1: 54-57.

10. Butler, $T_{+}$; Bell, W,; Levin, J.; Linh, N.: Typhoid fever, Arch lnt Med 1978; $138: 407-410$.

11. Laval, $E_{\text {; }}$ Vitalic, $J$.: Fiebre paratifoidea A y B. Estudio clínico de 666 casos. Revista Chilena de Infectología 1984; 2: 89-99.
12. Bancalori, A.; Banfi, A.: Fiebre tifoidea, experiencia en 831 casos pediátricos. Rev Med Chile 1978; 106: 609-612.

13. Gilman, R.; Terminel, M.; Levine, M.: Hornick, R.: Relatjve Efficacy of Blood, Urine, Rectal Swab, Bone and Rose Spot cultures for Recovery of Salmonella Typhi in Typhoid Fever, Iancet 1975 ; 1: 1211-1213

14. Cosanueva, $V_{.} ; G d, X$, Cavicchioli, G.; Oelker, $M_{\text {., }}$ Cofré, J.; Amigo, L.: Adenosina deaminasa sérica como ayuda diagnóstica en fiebre tifoidea. Estudio preliminar. Revista Chilena de Infectología 1990; $7: 71.75$.

15. Herrera, P.: Tregnaghi, M.; Valenzuela, R.; Prenzel, I.; Topelberg, S.: Cultivo de angre (micr ohemocultivo) en fiebre tifoidea $y$ en meningitis bacteriana aguda. Pediatría (Santiago) 1978; 21: 119-121.

16. Ortiz, V., Isibasi, A,; Garcio-Ortigoza, E.; Kumate, $J$.: Inmunoblot detection of class-specific humoral immuneresponse to outer membrane proteins isolated from Salmonella typhi in humans with thyphoid fever. I Clin Microbiol 1989; $27: 1640$ 1645 .

17. Rubin, F.A.; McWhirter, P.D.; Punjabi, N.H.; Lane, E.; Sudarmono, P.; Pulungsih, S.P.: Use of a DNA probe to detect Salmonella typhi in the blood of patients with typhoid fever. J Clin Microbiol 1989;27: 1112-1114.

18. Qodri, A.; Ghosh, S.; Prakash, K.; Kumar, R. Moudgil, K.D.: Tolwar, G.P.: Sandwich enzyme immunoassays for detection of Salmonello typhi. I Immunoassay 1990;11: 251-269.

19. Sadallah, F.; Brighouse, G.; Det Giudice, $G_{\text {; }}$; Drager-Dayal, R.; Hocine, M.; Lambert, P.H.: Production of specific monocional antibodies to Salmonella typhi flagellin and possible aplication to immunodiagnosis of typhoid fever. I Infect Dis 1990; 161 : 59-64.

20. Feygin and Cherry.: Texbook of Pediatric Infectious Diseases. Philadelphia WB Saunders and Co $1981 ; 1 ; 455-464$.

21. Baganhe, M.F.; Pego, A.; Lima, M.A.; Gaspar, E.V.; Cordeiro, A.R.: Serum and pleural adenosine deaminase correlation with lymphocytic populations. Chest 1990;97: 605-610.

22. Gentilini Marc Medicing Tropicale: 3 Ed. Paris Flammarion Med-Science 1982; 628 págs.

Esta publicación está disponible en copias de microfilms de 16 y $35 \mathrm{~mm}$ y microfjchas de $105 \mathrm{~mm}$, las que pueden solicitarse a:

University Microfilms International

300 North Zeeb Road

Ann Arbor, Michigan 48106, USA.

This joumal is also available in $16 \mathrm{~mm}$ microfilm, $35 \mathrm{~mm}$ microfilm and $105 \mathrm{~mm}$ microfilm copies through University Microfilms International, 300 North Zeeb Road, Ann Arbor, Michigan 48106, USA. 